\title{
FRANTZ FANON E A ESCOLHA PELA ARGÉLIA
}

Antonia Costa de Thuin é doutoranda do programa de Pós-graduação em Literatura, Cultura e Contemporaneidade da PUC-Rio, realizando em sua tese um mapeamento de autores e artistas visuais no continente africano.

\section{Resumo}

O presente artigo pretende demonstrar como a biografia de Frantz Fanon, e mais especificamente seu trabalho à frente da psiquiatria do Hospital de Blida, em Argel, influenciaram sua escrita e pensamento posterior, sobretudo em sua última obra, Os Condenados da Terra. Para tal, parto de cenas do filme A Batalha de Argel como descrições do que, ao ser escutado por Frantz Fanon em sua prática, serviu como disparador do discurso do livro.

\section{Palavras-chave}

Frantz Fanon. A Batalha de Argel. Os Condenados da Terra. Colonialismo.

Neste artigo pretendo discutir a biografia de Frantz Fanon, intelectual argelino nascido na Martinica - região que até hoje é província ultramarina francesa - que nos deixou importante trabalho sobre o processo das guerras de descolonização da África, e sobre como sua biografia interferiu diretamente em seu trabalho. Silviano Santiago discute muito a noção de descarrilamento, um momento da vida em que tudo muda, inclusive o trabalho, a obra realizada por uma pessoa. Defendo aqui que Frantz Fanon passou por dois descarrilamentos em sua vida, definidores de todo o seu trabalho posterior. Ao sair da Martinica para lutar ao lado dos soldados franceses na Segunda Guerra, Frantz Fanon se surpreendeu ao perceber que ali ele não era um membro da elite como em seu país de origem, mas simplesmente um negro, um colonizado. Esse primeiro choque gerou Peles Negras, Máscaras Brancas, sua tese e seu primeiro livro. Em 1953 foi nomeado pelo governo francês para atender como psiquiatra no hospital de Blida em Argel, onde teve contato com diversos pacientes que lutavam na ALN, e que tinham sobrevivido a batalhas e torturas cometidas pelo exército francês, que procurava então manter a Argélia colonizada.

Em seus textos, e também na produção feita a partir de seus trabalhos por outras pessoas, é patente e declarada a influência que a atuação como psiquiatra com sobreviventes da batalha de Argel e, portanto, o conhecimento da tortura sofrida por eles teve sobre seu trabalho posterior. Ao tomar consciência de situações de torturas 
sofridas e desumanização perpetradas pelos franceses, Frantz Fanon se coloca do lado dos argelinos na luta. Se filia à ALN, tornando-se uma espécie de embaixador da causa, visitando diversos países para falar sobre a descolonização. Nesse processo, e até falecer, em 1962, depois de acabar a escrita de Os Condenados da Terra, passa de um médico praticante a um intelectual engajado, parte da luta de libertação do país que escolheu, e pelo qual virou persona non grata na França. Ou seja, o processo de se dar conta, de ter consciência da tortura vivida não só nos interrogatórios, mas também no dia a dia, o transformou em argelino, fez com que para ele se tornasse necessário tomar um lado da luta.

Discutirei o impacto e a violência dessa escuta para Fanon, e como isso foi condicionante em sua obra. Uso para isso o filme Batalha de Argel, clássico cinematográfico que apresenta a luta pela libertação da Argélia e mostra essa violência ouvida por Fanon em imagens. Como uma ilustração do que Fanon ouviu e o fez falar que:

Essa vontade afirmada de tornar os últimos os primeiros, de fazer com que escalem (num passo rápido demais, dirão alguns) as famosas etapas que definem uma sociedade organizada, só pode triunfar se colocarmos na balança todos os meios necessários, inclusive, claro, a violência (FANON, 1962).

Para Fanon, a resposta é também com violência uma vez que tudo começa com violência. Nas palavras dele:

\begin{abstract}
Aquele a quem disseram constantemente que ele só compreendia a linguagem da força decide exprimir-se pela força. $\mathrm{Na}$ verdade, desde sempre o colono the apontou o caminho que deveria ser o seu, se quisesse libertar-se. O argumento escolhido pelo colonizado foi-lhe indicado pelo colono e, numa reviravolta irônica das coisas, é o colonizado que, agora, afirma que o colonizador só compreende a força (FANON, 1962).
\end{abstract}

Usam a força porque foi a força que aprenderam. A única linguagem que lhes foi permitida. Como Frantz Fanon ouviu em sua prática psicanalítica, toda a desumanização operada pelo colono teve efeito devastador e claro. Deu ao colonizado a única arma que ele passou a saber fazer uso. Tornou todo o processo violento e também um processo que iria até o fim por todos os meios necessários.

"Todos os meios necessários", a famosa frase de Fanon, dita em seu livro Os condenados da terra, é como um lado vê o outro. Frantz Fanon, ao se confrontar com esses depoimentos, com esses testemunhos em sua prática clínica, percebeu que ali 
existia uma força, uma violência necessária, percebeu também o caminho que estava sendo tomado, que precisava ser tomado, para a construção de algo novo. Mas que, ele mesmo sabia, talvez não fosse tão simples assim.

O primeiro trecho do filme que uso para essa discussão, é quase uma ilustração desse discurso de Frantz Fanon da reciprocidade da violência em Os Condenados da Terra, e mostra o discurso da guerrilha e de um coronel francês. Nesse trecho vemos uma entrevista coletiva. Repórteres sentados em uma espécie de auditório pequeno começam tirando muitas fotos, flashes ruidosos tomam a cena. $\mathrm{O}$ rosto de um homem franzino, de óculos e terno entra em close. Abre-se a cena e vemos pessoas de farda ao seu redor. Um dos fardados ordena o fim das fotografias. Começam a ser feitas perguntas. A primeira, feita por um jovem jornalista francês, é sobre as bombas escondidas nas sacolas das mulheres. $O$ jornalista pergunta se ele não acha isso uma atitude covarde. A resposta vem na mesma moeda. Seriam covardes as bombas de napalm? Que atacam aldeias sem defesa? Termina dizendo "nos deem bombardeiros. Que deixaremos vocês com nossas cestas". A segunda pergunta, feita por um inglês e traduzida, é sobre a possibilidade de vitória da FLN. A resposta fala que a FLN pode ganhar, mas a França não pode interromper o curso da história. A terceira é feita novamente por uma francesa. Diz que a ideia não era prendê-lo, mas sim a outro militante, e pergunta por que estava no endereço em que foi preso. Ao que o guerrilheiro responde que somente queria não ter estado ali. O coronel então, acende um cigarro e avisa que acabou a entrevista. Ele precisa trabalhar. Agora o franzino comandante da FLN pergunta se o espetáculo terminou e ouve que sim. Antes que produza o efeito contrário ao desejado. $\mathrm{O}$ coronel fala isso sem tirar o cigarro da boca. $\mathrm{E}$ o guerrilheiro é conduzido para fora da sala por dois soldados uniformizados. A seguir, vemos no mesmo espaço o coronel dar uma entrevista coletiva. Com óculos escuros e mãos postas sobre a cintura, o coronel, sempre em sua farda camuflada, começa respondendo a uma pergunta, feita por um francês, a respeito do suposto suicídio de Larbi Bem M'Hidi, se seria possível ter acontecido tal como descreveu o porta voz do ministro. Três fotógrafos tiram fotos em close do coronel enquanto ele ouve a pergunta, que é respondida apenas com a sugestão de se perguntar isso ao porta-voz. Seguida por uma elegia a Bem M'Hidi, que era fiel a seus ideais, segundo as palavras do coronel. A segunda pergunta trata dos resultados obtidos e de seus métodos. Ao que o coronel, sempre com os óculos escuros, fala que o sucesso depende dos métodos. Então um senhor mais velho levanta para fazer a sua pergunta. Bloco de anotações na mão. E pede 
que se pare de usar declarações vagas e se use a palavra real do que acontece: tortura. Ao que o coronel pede que ele faça uma pergunta. E ouve do jornalista que as perguntas já foram feitas. Ele só gostaria de respostas mais precisas. O coronel, sempre com a postura ereta, mãos na cintura, começa a falar tentando ser mais direto, como pedido. Insiste que não falam em tortura, mas em interrogatório. Que precisa de resultados no primeiro dia, pois a FLN muda seus planos 24 h após a prisão de um dos seus. E segue, tirando os óculos e se dirigindo aos jornalistas, falando do círculo vicioso. Dá alguns passos na sala. Senta-se na mesa e fala "a questão é que a FLN nos quer fora da Argélia. Nós somos soldados em uma batalha, não somos nazistas. Para ser preciso. Pergunto a vocês. A França deve permanecer na Argélia? Se a resposta for afirmativa, devemos aceitar todas as consequências"

Nas duas respostas ouvidas, percebe-se bem o que Frantz Fanon quer dizer quando fala em "todos os meios necessários". É um caminho de mão dupla, como escreve ao descrever a situação do colonizado. Isso é o que se espera de um colonizado. Nas duas respostas, aparecem todos os meios necessários. Tanto a FLN quanto a metrópole desde o princípio estão preparadas para usar todos os meios. O colonizado não tem outra forma de se proteger que não seja também atacando com todas as suas forças.

Uma das violências ouvidas por Fanon em sua prática é a violência da separação total da cidade entre cidade do colono e do colonizador. A única interface entre as duas sendo a polícia. Não há outra interface que aproxime os dois mundos. O colonizador, na maior parte das colônias, coloca um estatuto do indigenato - colônias portuguesas e francesas têm seus similares, com descrições do que seria necessário para um indígena alçar ao status de assimilado, ou próximo de um cidadão - e relega o colonizado a um espaço fechado em que os direitos são controlados, e os deveres são todos.

Frantz Fanon descreve em seu livro a separação absoluta entre a cidade do colonizador e do colonizado. A existência de ruas, de calçadas, de espaços limpos e arejados por um lado, e a inexistência de organização e de serviços básicos por outro. Cito:

A zona habitada pelos colonizados não é complementar da zona habitada pelos colonos. Essas duas zonas se opõem, mas não ao serviço de uma unidade superior. Regidas por uma lógica puramente aristotélica, elas obedecem ao princípio de exclusão recíproca: não há conciliação possível, um dos termos está sobrando. A cidade do colono é uma cidade firme, toda de pedra e de ferro. É uma cidade iluminada, asfaltada, em que as lixeiras transbordam restos desconhecidos, jamais vistos ou mesmo sonhados. [...] A cidade do colono é uma cidade satisfeita, 
preguiçosa, sempre repleta de coisas boas em seu interior. A cidade do colono é uma cidade de brancos, de estrangeiros.

A cidade do colonizado, ou ao menos a cidade indígena, a cidade negra, a medina, a reserva, é um lugar de má reputação, povoado de homens de má reputação. As pessoas nascem não importa onde, não importa como. Morrem não importa onde, não importa de que. É um mundo sem intervalos, os homens ficam uns sobre os outros, as casas umas sobre as outras. [...] O colonizado olha para a cidade dos colonos com luxúria, com inveja. Sonha possuir. Todos os modos de posse: sentar na mesa do colono, deitar na cama do colono, com sua mulher se possível. [...], não há um só colonizado que não sonhe ao menos uma vez por dia com estar no lugar do colono (FANON, 1962).

Cidades cercadas, separadas, violência na separação total de corpos, no estabelecimento de áreas onde existe e onde não existe cidadania. A única mediação é a da polícia e do exército, os colonizados não têm outra forma de lidar com o colono sem ser através da mediação violenta da polícia. Não recebem outro tratamento e não têm diálogo. Fanon escuta isso e usa isso em seu livro, em sua teoria. Coloca a importância que tem para a formação de um sujeito a impossibilidade de participar da cidade.

Volto então ao filme, com mais uma cena onde isso é explicitado, a cena da greve dos colonizados. Nesta cena, é apresentada uma greve dos colonizados, que se recusam a trabalhar para os colonos, como forma de buscar uma saída política, e como resposta, mesmo sua pouca mobilidade é cortada. Vemos serem colocadas grades em toda a fronteira entre a Casbah - como era chamada a cidade dos colonizados na Argélia, os subúrbios de Argel. Historicamente, as Casbah são as cidades muradas árabes do norte da África - e a cidade dos colonos, explicitando no cinema o que foi constatado e descrito por Frantz Fanon em seu texto.

A cena começa com a declaração do prefeito de Argel a respeito do gradeamento da Casbah e do endurecimento dos controles de fronteira sendo ouvida ao fundo, como que veiculada pelos alto-falantes que são vistos posicionados na cidade. Vemos ao mesmo tempo as grades e tapumes subindo, cercas sendo posicionadas e filas de pessoas saindo dessa área gradeada dali para trabalhar - a cidade dos colonizados não tem trabalho, é uma cidade de joelhos, como diz Fanon - aguardando o controle de passagem feito pelos guardas. Soldados revistam as pessoas e as empurram para ficarem em fila. Um deles pergunta a um homem se ele voltará para a caserna. Uma mulher de burca desce as escadas, um soldado faz menção de revista-la e ela reclama em árabe. $\mathrm{O}$ outro soldado pergunta "você não sabe que não podemos encostar nas mulheres deles?"

Nesta cena percebemos que tudo são posses de um lado ou de outro, os espaços e as pessoas têm donos. Mesmo as mulheres. São as mulheres dos colonos ou dos 
colonizados. E aqui podemos voltar ao texto de Fanon, que declarava que na pior das hipóteses, o colonizado repetiria as estruturas do colono ao tomar o poder. Repetiria o machismo, a posse das mulheres, repetiria a opressão a alguém, mudando somente quem seria o alguém.

Os colonizados precisam do acesso à cidade do colono para trabalhar e têm negada qualquer outra entrada nesse espaço. São gradeados, trancados e impedidos de passar. Na continuação, homens - os que estavam em greve - andam sob supervisão dos soldados para dentro de caminhões, em grupos grande, em uma espécie de zona neutra entre a cidade do colono e a Casbah, tratados como gado, impedidos de andar sem supervisão na cidade do colono, de entrar naquele espaço sem ser para executar a função para a qual foram contratados. Um homem é interpelado por um soldado, que quer saber se ele faz parte do movimento grevista. Ele insiste que não, mas o soldado não acredita nele, e faz com que outro soldado o escolte para um outro caminhão, onde estão sendo colocados os suspeitos de participarem da FLN.

A tortura também entra como questão para Fanon. A tortura que torna o colonizado menos do que uma pessoa. Que força o colonizado a se reconhecer no colono, o obriga a perder sua identidade, a não ser mais humano; a escuta da tortura também influencia o trabalho e a teoria do autor. Ao descrever e perceber a tortura, descreve e percebe como essa violência contida nela tira toda opção ao colonizado:

O colonizado, quando torturado, quando vê sua mulher ser morta ou estuprada, não vai se queixar com ninguém. O governo que o oprime poderá muito bem nomear a cada dia comissões de inquérito e de informação. Para o colonizado, essas comissões não existem. [...] $\mathrm{O}$ trabalho do colono é tornar impossíveis mesmo os sonhos de liberdade do colonizado. O trabalho do colonizado é imaginar todas as combinações possíveis para negar o colono (FANON, 1962).

O colono busca impedir de todas as formas a existência do colonizado. Como resposta, a única possível, negar a existência do colono, expulsá-lo. Fanon escuta a tortura e só vê uma saída.

Encerro o trabalho então descrevendo uma cena que é na verdade o início do filme. Os últimos serão os primeiros na luta e na força simbólica de suas ações. O filme abre com o término de uma sessão de tortura, antes mesmo de passarem os créditos. Vemos uma sala com um tonel do lado direito. Macas encostadas nas paredes de azulejos brancas e muito sujas. Um homem só de cuecas sentado em um banco no meio dessa sala, três soldados arrumando coisas nas macas, o torturado, muito magro, mãos 
nos joelhos com um olhar vazio, no que parece ser o momento depois de falar o que interessava aos soldados, é esfregado por um soldado no que parece um instante de cuidado. Em seguida dão a ele café "você vai se sentir melhor", dizem. Ele recusa o café. O levantam e vemos como está magro, com marcas de queimadura no peito esquerdo. Entra o coronel e pede o endereço que ele deu. Manda que fique em pé sem ajuda, e o obriga a vestir roupas militares francesas e ir com os soldados à Casbah, ver o resultado do que falou, ver seus companheiros serem presos. Um soldado coloca um boné militar nele e faz uma ironia "integração!". A câmara foca em seu rosto quando ouve o coronel falar. E ele berra "não!!". Vemos um homem fraco, quebrado, sem roupas no início. Com os pés em uma bacia d’água, frágil, que aceita as ordens sem forças para reagir, depois de ouvir que "finalmente abriu a boca". Quando coloca o uniforme e sabe que terá de ver seus companheiros serem presos, tenta fugir, olhando para seu próprio reflexo, como sem encontrar seu próprio reflexo.

A violência de reduzir o colonizado ao não humano. As táticas nazistas, e a polícia como única mediação estão presentes, apesar da negação do coronel na primeira cena apresentada, ao dizer que ele combateu o nazismo. O filme mostra o tempo todo a humilhação. Frantz Fanon discorreu sobre isso em Os Condenados da Terra, sobre a redução do colonizado à condição de não humano. Não tratava apenas das prisões, mas também do dia a dia, porém nessa cena, em que toda a identidade do prisioneiro é apagada, ele tendo que usar mesmo o uniforme dos seus algozes, tendo que caminhar ao lado deles - os soldados riem dele, colocando o quepe e berrando "olha a integração!". Essa humilhação o coloca em situação de desespero mais aparente do que a própria tortura. A violência de obrigar o indígena a sair de sua cultura, de seu povo, para ser um francês, e ainda assim um francês de segunda categoria, pois assimilado e jamais cidadão.

Quis aqui demonstrar como a escuta de Fanon dessas humilhações foi crucial para sua escrita posterior. Uso as cenas como a descrição possível dessas humilhações para quem não viveu elas. $\mathrm{O}$ cinema nos permite esse contato, nos permite ter a ilusão de ver isso acontecer com outro ser humano, nos ilustra o que foi ouvido por Fanon e permite entender como sua escuta transformou o que ouviu no que posteriormente escreveu. 


\title{
Bibliografia
}

FANON, Frantz. Peau noire masques blancs. Paris, Éditions du Seuil, 1952.

, Frantz. Les Damnés de la terre. Montréal, Bibliotéque Paul-Émile-Boulet, 2002.

PONTECORVO, Gillo, A Batalha de Argel, Produção de Gillo Pontecorvo, Argélia/Itália 1966, $121 \mathrm{~min}$.

WALLERSTEIN. Ler Fanon no século XXI. Revista Crítica de Ciências Sociais. n.82 (2008).

\section{FRANTZ FANON AND THE CHOICE FOR ALGERIA}

\begin{abstract}
This paper demonstrates how Frants Fanon's biography, more specifically the period he worked as a psychiatrist at Blida Hospital, in Algiers, influenced what he wrote and worked on thereafter, specially his last book, The Wretched of the Earth. To do so, I use scenes from the movie The Battle of Algiers as descriptions of what, when heard by Frantz Fanon in his practice, was the trigger for the speech in the book.
\end{abstract}

\section{Keywords}

Frantz Fanon. The Battle of Algiers. The Wretched of the Earth. Colonialism. 